\title{
Mitochondrial targeted antioxidants, mitoquinone and SKQ1, not vitamin C, mitigate doxorubicin-induced damage in H9c2 myoblast: pretreatment vs. co-treatment
}

Brian Sacks ${ }^{\dagger}$, Halil Onal ${ }^{\dagger}$, Rose Martorana, Amogh Sehgal, Amanda Harvey, Catherine Wastella, Hafsa Ahmad, Erin Ross, Adona Pjetergjoka, Sachin Prasad, Robert Barsotti, Lindon H. Young and Qian Chen * (D)

\begin{abstract}
Background: Preconditioning of the heart ameliorates doxorubicin (Dox)-induced cardiotoxicity. We tested whether pretreating cardiomyocytes by mitochondrial-targeted antioxidants, mitoquinone (MitoQ) or SKQ1, would provide better protection against Dox than co-treatment.

Methods: We investigated the dose-response relationship of MitoQ, SKQ1, and vitamin C on Dox-induced damage on H9c2 cardiomyoblasts when drugs were given concurrently with Dox (e.g., co-treatment) or $24 \mathrm{~h}$ prior to Dox (e.g., pretreatment). Moreover, their effects on intracellular and mitochondrial oxidative stress were evaluated by 2,7dichlorofluorescin diacetate and MitoSOX, respectively.

Results: Dox $(0.5-50 \mu \mathrm{M}, n=6)$ dose-dependently reduced cell viability. By contrast, co-treatment of MitoQ (0.05$10 \mu \mathrm{M}, n=6)$ and SKQ1 $(0.05-10 \mu \mathrm{M}, n=6)$, but not vitamin C (1-2000 $\mu \mathrm{M}, n=3)$, significantly improved cell viability only at intermediate doses $(0.5-1 \mu \mathrm{M})$. MitoQ $(1 \mu \mathrm{M})$ and SKQ1 $(1 \mu \mathrm{M})$ significantly increased cell viability to $1.79 \pm 0.12$ and $1.59 \pm 0.08$ relative to Dox alone, respectively (both $p<0.05$ ). Interestingly, when given as pretreatment, only higher doses of MitoQ $(2.5 \mu \mathrm{M}, n=9)$ and SKQ1 $(5 \mu \mathrm{M}, n=7)$ showed maximal protection and improved cell viability to $2.19 \pm 0.13$ and $1.65 \pm 0.07$ relative to Dox alone, respectively (both $p<0.01$ ), which was better than that of cotreatment. Moreover, the protective effects were attributed to the significant reduction in Dox-induced intracellular and mitochondrial oxidative stress.
\end{abstract}

Conclusion: The data suggest that MitoQ and SKQ1, but not vitamin C, mitigated DOX-induced damage. Moreover, MitoQ pretreatment showed significantly higher cardioprotection than its co-treatment and SKQ1, which may be due to its better antioxidant effects.

Keywords: Doxorubicin, Cardiotoxicity, Mitochondrial-targeted antioxidants, Vitamin C, Oxidative stress

\footnotetext{
* Correspondence: qianch@pcom.edu

${ }^{\dagger}$ Brian Sacks and Halil Onal contributed equally to this work.

Department of Bio-Medical Sciences, Philadelphia College of Osteopathic

Medicine, 4170 City Avenue, Philadelphia, PA 19131, USA
}

(C) The Author(s). 2021 Open Access This article is licensed under a Creative Commons Attribution 4.0 International License, which permits use, sharing, adaptation, distribution and reproduction in any medium or format, as long as you give appropriate credit to the original author(s) and the source, provide a link to the Creative Commons licence, and indicate if changes were made. The images or other third party material in this article are included in the article's Creative Commons licence, unless indicated otherwise in a credit line to the material. If material is not included in the article's Creative Commons licence and your intended use is not permitted by statutory regulation or exceeds the permitted use, you will need to obtain permission directly from the copyright holder. To view a copy of this licence, visit http://creativecommons.org/licenses/by/4.0/. The Creative Commons Public Domain Dedication waiver (http://creativecommons.org/publicdomain/zero/1.0/) applies to the data made available in this article, unless otherwise stated in a credit line to the data. 


\section{Introduction}

Doxorubicin (Dox) is a widely used anti-cancer drug due to its ability to generate free radicals and interfere with DNA replication on cancer cells. However, Dox also induces severe cardiotoxicity, such as cardiomyopathy and associated heart failure [1, 2]. Dexrazoxane is a drug used to reduce Dox-induced cardiotoxicity possibly by chelating iron and inhibiting Dox-topoisomerase II (TOP II) interaction. On the other hand, dexrazoxane can cause hematological toxicity, gastrointestinal discomfort, and even increase the risk of developing a second primary malignancy, which limit its use in women with advanced or metastatic breast cancer [3, 4]. Therefore, it is integral to identify new strategies to protect the heart against Dox during chemotherapy.

Dox induces cardiac cell damage and/or apoptosis through the same mechanisms as its ability to kill cancer cells. It intercalates between DNA strands as well as inhibits the function of TOP II, leading to blockage of DNA replication and transcription and breakage of DNA double strand $[3,5]$. This is somewhat selective for cancer cells because they are replicating more than most normal cells. Dox also induces cardiotoxicity by accumulating within the mitochondria and increasing reactive oxygen species (ROS) production [6]. Dox can additionally lead to a reduction in glutathione peroxidase and catalase levels to decrease endogenous anti-oxidant capacity [7]. Another feature is that Dox can interact with cardiolipin to disrupt proper functioning of electron transport chain in mitochondria $[1,2]$. Because cardiac tissue is most abundant in mitochondria compared to other tissues, the heart is the most susceptible to Doxinduced mitochondrial damage. Thus, protection of mitochondria against Dox-induced oxidative stress would be an effective strategy to mitigate cardiotoxicity under Dox treatment.

Vitamin $\mathrm{C}$ is a representative common anti-oxidant, which has been widely used, in daily life. Most studies have shown vitamin $\mathrm{C}$ can protect the heart against Dox by enhancing antioxidant and anti-inflammation effects and reducing cellular damage and apoptosis in vitro and in vivo studies $[5,8]$. However, higher concentrations of vitamin $C$ have been suggested to be pro-oxidant which can damage the cell [9]. Furthermore, vitamin $C$ may not specifically target the mitochondria when compared to mitochondria-targeted antioxidants, such as mitoquinone (MitoQ) and 10-(6'-plastoquinonyl) decyltriphenylphosphonium (SKQ1). MitoQ and SKQ1 are a derivative of ubiquinone or plastoquinone conjugated to decyl-triphenylphosphonium cation (TPP), respectively $[10,11]$. TPP is a lipophilic cation, and conjugation allows the compound to concentrate in the mitochondria with ease due to the powerful electrical gradient created between the cationic TPP and drastic negative membrane potential of the mitochondria (eg., $-160 \mathrm{mV}$ to $-180 \mathrm{mV}$ ) [10]. Moreover, MitoQ is available over counter for antioxidant supplement use and SKQ1 (Visomitin) is approved to treat dry eye conditions in Russia [10]. It's known that MitoQ reduces the production of lipid peroxyl radicals and prevents lipid peroxidation [12]. MitoQ is also demonstrated to reduce Doxinduced damage in $\mathrm{H} 9 \mathrm{c} 2$ cells and cardiomyopathy in animal studies [13]. By contrast, SKQ1 has been found to form a complex with cardiolipin in order to prevent lipid peroxidation [14]. SKQ1 also shows a four-fold higher decrease in peroxyl radicals than MitoQ in vitro studies [11]. However, the effects of SKQ1 on Doxinduced cardiotoxicity have not been well studied. Thus, it is worthwhile to investigate if SKQ1 would provide the same or better cardioprotection against Dox than vitamin C or MitoQ. Since MitoQ and SKQ1 can also serve as pro-oxidants at higher concentrations [15], it is important to understand their dose-response relationship related to those effects. Recently, two labs have indicated that preconditioning of cardiomyocytes by transient hypoxia/reoxygenation or remote ischemic preconditioning ameliorates Dox-induced cardiotoxicity and preserves mitochondrial functions $[16,17]$. Moreover, MitoQ pretreatment is found to upregulate antioxidant genes, attenuate mitochondrial oxidative stress, and prevent mitochondrial DNA depletion under intestinal ischemia/ reperfusion conditions [18]. However, there is lack of research demonstrating the effects of mitochondriatargeted antioxidants when given as pretreatment on Dox-induced cardiac cell damage.

In this study, we first determined dose-dependent effects of Dox on the cellular damage in $\mathrm{H} 9 \mathrm{c} 2$ cells. We also compared Dox's effects to hydrogen peroxide $\left(\mathrm{H}_{2} \mathrm{O}_{2}\right)$, a common oxidative stress inducer. We then compared the effects of vitamin C, MitoQ, or SKQ1 on Dox-induced cell damage when drugs were given concurrently with Dox (e.g., co-treatment) or $24 \mathrm{~h}$ prior to adding Dox (e.g., pretreatment). Lastly, we investigated the effects of Dox alone or combined with MitoQ or SKQ1 on intracellular and mitochondrial oxidative stress.

\section{Methods \\ H9c2 myoblast}

Rat H9c2 cells (CRL-1446, American Type Culture Collection (ATCC), Manassas, VA) were cultured in $75 \mathrm{~cm}^{2}$ flasks and petri dishes using $4.5 \mathrm{~g} / \mathrm{mL}$ glucose DMEM with $10 \%$ fetal bovine serum and $1 \%$ penicillin streptomycin solution (Corning, Fisher Scientific, Waltham, MA) at $37{ }^{\circ} \mathrm{C}$ and $5 \% \mathrm{CO}_{2}$ in a humid incubator. Cell media was changed every 2-3 days till cells reached 70 $80 \%$ confluence for passaging to prevent the loss of differentiation potential according to the ATCC instruction. Meanwhile, some cells were harvested for 
experiments. Cell density after the collection was counted using 0.3\% trypan blue kit (Sigma-Aldrich, St. Louis, MO) and plated $2 \times 10^{4}$ cells per well in a 96-well plate. After seeding, H9c2 cells were incubated for $24 \mathrm{~h}$ before treatments were administered. We used H9c2 cells within 5-20 passages for all the experiments because control cells showed similar morphology under light microscopy (200X). Cell responses to all tested compounds were very close across all the passages. All the procedures for maintaining the cell line and conducting experiments were carried out in a cell culture hood with sterile techniques. Cells were checked for contamination, morphology alteration, and confluence by microscopy every day. When cells were contaminated or deformed, all the flasks, media, and cell plates were immediately discarded. The cell incubator was cleaned and disinfected. Then, a new H9c2 cell line was freshly restarted. All experiment groups included a non-treated cell control to observe any physical, chemical, and physiological changes among groups and cell passages. To prevent chemical contamination, different treatments were added to cells in separate columns on a cell plate. Moreover, pipette tips were frequently changed during procedures.

\section{Experimental groups}

\section{Dox or $\mathrm{H}_{2} \mathrm{O}_{2}$ induced cell damage}

Dox $(0.5-50 \mu \mathrm{M} ; \mathrm{M} . \mathrm{W} .=579.98 \mathrm{~g} / \mathrm{mol}$, Sigma-Aldrich, St. Louis, MO) or $\mathrm{H}_{2} \mathrm{O}_{2}(100-600 \mu \mathrm{M}$; M.W. $=34.01 \mathrm{~g} /$ mol, Sigma-Aldrich, St. Louis, MO) and solvent control (e.g., medium) were applied to cells which were in 1day-old medium (e.g., after cell seeding for $24 \mathrm{~h}$ ) to determine cell damage. When cells were pretreated with testing compounds, fresh medium was added after washing out the testing drugs. We have found that fresh medium would reduce the cell damage induced by $\mathrm{H}_{2} \mathrm{O}_{2}$. Therefore, Dox $(0.1-50 \mu \mathrm{M})$ or $\mathrm{H}_{2} \mathrm{O}_{2}$ (100$600 \mu \mathrm{M})$ and solvent control (e.g., medium) were applied to cells with fresh medium to determine if there is any different effects of Dox or $\mathrm{H}_{2} \mathrm{O}_{2}$ on cells with fresh medium when compared to that with 1-day-old medium. Cells were then incubated in Dox or $\mathrm{H}_{2} \mathrm{O}_{2}$ for $24 \mathrm{~h}$ before performing biochemical assays.

\section{Vitamin C treatments}

First, vitamin C $(1-2000 \mu \mathrm{M} ; \mathrm{M} . \mathrm{W} .=276.12 \mathrm{~g} / \mathrm{mol}$, Sigma-Aldrich, St. Louis, MO) was administered to cells alone to determine if vitamin $\mathrm{C}$ itself caused any cell damage. Then, vitamin $C(1-2000 \mu \mathrm{M})$ was administered with Dox $(40 \mu \mathrm{M})$ as a co-treatment to evaluate if vitamin $\mathrm{C}$ would exert any protection against Dox. Cells were incubated for another $24 \mathrm{~h}$ before performing biochemical assays.

\section{MitoQ treatments}

MitoQ $\quad(0.05-10 \mu \mathrm{M} ; \quad$ M.W. $=678.8 \mathrm{~g} / \mathrm{mol}$, Cayman Chemical, Ann Arbor, Michigan) was applied to cells alone to test if MitoQ itself caused any cell damage. Furthermore, MitoQ was administered with Dox $(40 \mu \mathrm{M})$ as a co-treatment to evaluate if MitoQ would exert any protection against Dox. We also used MitoQ as a pretreatment by adding MitoQ to cells for $24 \mathrm{~h}$. Then MitoQ was removed and cells were washed with PBS twice, then fresh medium was added prior to administration of Dox $(40 \mu \mathrm{M})$. Cells were incubated for another $24 \mathrm{~h}$ before performing biochemical assays.

\section{SKQ1 treatments}

Similarly as MitoQ, SKQ1 $(0.05-10 \mu \mathrm{M} ; \mathrm{M} . \mathrm{W} .=617.6 \mathrm{~g} /$ mol, Cayman Chemical, Ann Arbor, Michigan) was applied to cells alone to test if SKQ1 itself caused any cell damage. Furthermore, SKQ1 was administered as a cotreatment or pretreatment to determine if SKQ1 exerted any cell protection against Dox $(40 \mu \mathrm{M})$.

\section{Biochemical assays \\ Cell viability analysis by cell counting kit-8 (CCK-8)}

CCK-8 (Dojindo Molecular Technologies, Rockville, MD) was used to evaluate cell viability based on intracellular dehydrogenase activity. Tetrazolium salt is reduced by dehydrogenases in live cells to form formazan, which is soluble in tissue, and the amount of formazan dye generated by dehydrogenases is directly proportional to the number of living cells. After the corresponding treatments described above, the medium was removed, and cells were washed twice with PBS, then $100 \mu \mathrm{l}$ fresh medium was added. CCK reagent $(10 \mu \mathrm{l})$ was added to each well and cells were incubated for $4 \mathrm{~h}$ to allow the reaction to complete. Absorbance was measured at 450 $\mathrm{nm}$ with ELISA plate reader, and the ratio of absorbance in treated vs. non-treated (e.g., medium) control or Dox alone was determined.

\section{Cell viability by calcein assay}

To further confirm cell damage caused by Dox or $\mathrm{H}_{2} \mathrm{O}_{2}$, calcein assay was used to stain live cells. Calcein is a cell permeable dye that is converted to green fluorescent calcein after acetoxymethyl ester is hydrolyzed by intracellular esterase in live cells. Calcein (Thermo Fisher Scientific, Waltham, MA) was prepared using PBS. After treatment of Dox or $\mathrm{H}_{2} \mathrm{O}_{2}$ for $24 \mathrm{~h}$, culture media was removed. Calcein solution $(3 \mu \mathrm{M})$ was added to each well and fluorescence intensity was measured at $485 \mathrm{~nm} /$ $535 \mathrm{~nm}$ with Fluoroskan Ascent CF after incubation for $30 \mathrm{~min}$. The ratio of fluorescence intensity in treated vs. non-treated (e.g., medium) control was determined. 


\section{Intracellular ROS analysis by 2, 7-dichlorofluorescin diacetate (DCFDA)}

DCFDA (Thermo Fisher Scientific, Waltham, MA) is a fluorogenic dye that allows quantification of hydroxyl, peroxyl and other ROS activity within the cell. Cell permeable DCFDA is non- fluorescent compound which is first deacylated by cellular esterase inside live cells, and then oxidized by intracellular ROS to DCF, which is a highly fluorescent compound that can be detected by fluorescence spectrometry. First, H9c2 cells were loaded with DCFDA after they were incubated with100 $\mu$ of DCFDA $(25 \mu \mathrm{M})$ for $45 \mathrm{~min}$. Then, DCFDA reagent was removed and $100 \mu \mathrm{l}$ of DMEM medium was added to each well. Thereafter, cells were treated with Dox (0.1$50 \mu \mathrm{M})$ or Dox $(40 \mu \mathrm{M})$ combined with MitoQ or SKQ1 to determine the effects of Dox alone or co-treatment of drugs (MitoQ or SKQ1) on intracellular ROS. In another set of experiments, DCFDA was added to cells after pretreatment of MitoQ or SKQ1 or vehicle for $24 \mathrm{~h}$. After removing DCFDA, cells were treated with Dox $(40 \mu \mathrm{M})$ to determine the effects of MitoQ or SKQ1 pretreatment on Dox-induced intracellular ROS. Fluorescence intensity was measured at $485 \mathrm{~nm} / 535 \mathrm{~nm}$ by Fluoroskan Ascent CF at $10 \mathrm{~min}$ and $24 \mathrm{~h}$ after cells were incubated with Dox, The intracellular ROS levels were expressed as the ratio between Dox to non-treated control or between pretreatment to Dox, respectively.

\section{Mitochondrial superoxide (SO) analysis by MitoSOX}

MitoSOX (Thermo Fisher Scientific, Waltham, MA) is a novel fluorogenic dye used for detection of SO within the mitochondria of live cells. The lipophilic, positively charged TPP moiety within MitoSOX allows the dye to concentrate within the mitochondrial matrix pending on high mitochondrial membrane potential in live cells. The dye is oxidized by SO to produce red fluorescence. First, cells were treated by Dox $(0.1-50 \mu \mathrm{M})$ alone, Dox $(40 \mu \mathrm{M})$ co-treated with MitoQ or SKQ1, or Dox $(40 \mu \mathrm{M})$ following pretreatment of MitoQ or SKQ1. After $24 \mathrm{~h}$, the medium was removed and cells were washed with PBS. Thereafter, $100 \mu \mathrm{l}$ MitoSOX $(5 \mu \mathrm{M})$ reagent was added to each well and incubated for $15 \mathrm{~min}$. Fluorescence intensity was measured after changing the incubation solution to medium at $531 \mathrm{~nm} / 593 \mathrm{~nm}$ with Fluoroskan Ascent CF. The mitochondrial SO levels were expressed as the ratio between Dox to non-treated control or between pretreatment to Dox, respectively.

\section{Statistical analysis}

All experiments were performed in triplicate and repeated at least three times. The data was expressed by mean $\pm \mathrm{SE}$. The data were analyzed using ANOVA followed by Student Newman Keuls and $p$ value of < 0.05 was considered as statistical significance.

\section{Results}

Dox dose-dependently decreased cell viability similarly as $\mathrm{H}_{2} \mathrm{O}_{2}$, but culture medium did not affect its cytotoxicity

The effects of Dox $(0.5-50 \mu \mathrm{M})$ or $\mathrm{H}_{2} \mathrm{O}_{2}(100-600 \mu \mathrm{M})$ on $\mathrm{H} 9 \mathrm{c} 2$ cell viability under fresh and 1-day old medium is shown in Fig. 1A-C. Compared to non-treated control cells, treatment with Dox doses ranging from $5 \mu \mathrm{M}$ to $50 \mu \mathrm{M}$ significantly reduced cell viability (see Fig. 1A-B). The reduction was dose-dependent. However, the doseresponse of Dox on cell viability was not significantly different when Dox was directly added to 1-day-old medium $(n=10)$ or fresh medium $(n=3)$. Dox $(40 \mu \mathrm{M})$ significantly reduced cell viability to $0.40 \pm 0.03$ or $0.37 \pm 0.04$ under old or fresh medium, respectively (both $p<0.05$ compared to non-treated control). Similarly, $\mathrm{H}_{2} \mathrm{O}_{2}(100-600 \mu \mathrm{M})$ reduced cell viability in a dose-dependent manner (see Fig. 1A and C). However, the cytotoxicity induced by $\mathrm{H}_{2} \mathrm{O}_{2}(500 \mu \mathrm{M}$ and $600 \mu \mathrm{M})$ was significantly lower when $\mathrm{H}_{2} \mathrm{O}_{2}$ was added to 1-dayold medium $(n=8)$ compared to those in fresh medium $(n=6)$. After incubation of $600 \mu \mathrm{M} \mathrm{H}_{2} \mathrm{O}_{2}$ for $24 \mathrm{~h}$, cell viability relative to non-treated control in 1-day-old medium $(0.24 \pm 0.08, n=8, p<0.01)$ was significantly lower than in fresh medium $(0.95 \pm 0.10, n=6)$.

We further confirmed the cell damage by Dox and $\mathrm{H}_{2} \mathrm{O}_{2}$ in 1-day old medium by calcein staining (see Fig. 2A-B). We found that cells after incubation of Dox or $\mathrm{H}_{2} \mathrm{O}_{2}$ exhibited much less green staining when compared to non-treated control (see Fig. 2A). Also, Dox $(n=6)$ and $\mathrm{H}_{2} \mathrm{O}_{2}(n=5)$ reduced cell viability in a dosedependent manner (see Fig. 2B), and the effects were similar as those evaluated by CCK assay. Dox $(40 \mu \mathrm{M})$ and $\mathrm{H}_{2} \mathrm{O}_{2}(600 \mu \mathrm{M})$ significantly reduced cell viability to $0.49 \pm 0.09$ and $0.21 \pm 0.02$, respectively, when compared to the non-treated control (both $p<0.01$ ). In the following experiments, Dox $(40 \mu \mathrm{M})$ was used with antioxidants to determine if vitamin C, SKQ1, or MitoQ would protect cells against Dox-induced cell damage.

\section{Antioxidants alone did not induce any cell damage}

The effects of antioxidants alone on cell viability are illustrated in Fig. 3. All three antioxidants $(n=3-4)$ slightly increased cell viability which was determined by measuring live cell dehydrogenase activity. Moreover, higher dose MitoQ $(10 \mu \mathrm{M})$ showed a slight reduction in cell viability. However, there was no significant difference when compared to non-treated control or each other.

\section{Mitochondrial targeted antioxidants, but not vitamin C, protected H9c2 cells against Dox when given as co- treatment}

The effects of the different combinations of antioxidants with $40 \mu \mathrm{M}$ Dox on cell viability is shown in Fig. 4A-B. Co-treatment of MitoQ or SKQ1 with Dox showed more 


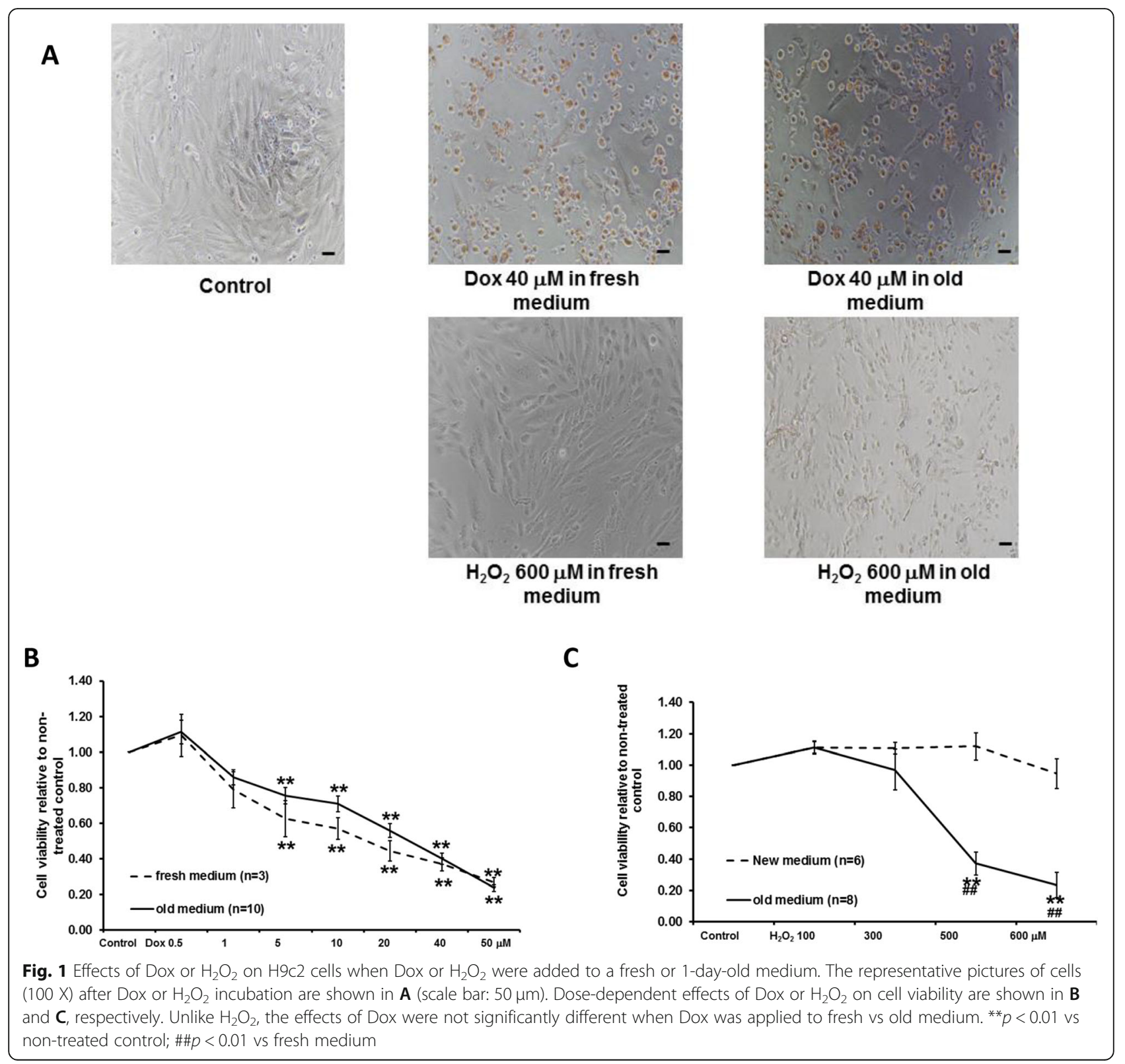

live cells than those in Dox alone or vitamin $\mathrm{C}$ treatment (see Fig. 4A). Also, we found that vitamin C (1$2000 \mu \mathrm{M}, n=3)$ did not show any increase in cell viability at any given dose. By contrast, SKQ1 $(0.05-10 \mu \mathrm{M}$, $n=6)$ and MitoQ $(0.05-10 \mu \mathrm{M}, n=6)$ increased cell viability in a dose-dependent manner (see Fig. 4A-B). MitoQ showed slightly better protective effects than SKQ1, but did not show any significant difference between them. MitoQ $(1 \mu \mathrm{M})$ and SKQ1 $(1 \mu \mathrm{M})$ significantly increased cell viability to $1.79 \pm 0.12$ and $1.59 \pm$ 0.08 , respectively, when compared to Dox (both $p<$ $0.05)$. Interestingly, we found the protective effects exhibited by SKQ1 and MitoQ were either reduced or lost when the doses were higher than $1 \mu \mathrm{M}$, respectively.
MitoQ and SKQ1 provided better protection against Dox when given as pretreatment than co-treatment

The effects of pretreating cells by SKQ1 and MitoQ on Dox-induced cell damage are shown in Fig. 5A-B. Pretreatment of MitoQ or SKQ1 showed more live cells than those in Dox alone (see Fig. 4A). Moreover, we found that SKQ1 $(0.05-10 \mu \mathrm{M}, n=7)$ and MitoQ (0.05$10 \mu \mathrm{M}, n=9)$ increased cell viability in a dose-dependent manner. MitoQ $(5 \mu \mathrm{M})$ and SKQ1 $(5 \mu \mathrm{M})$ exerted the maximal effect and showed a significant increase in cell viability ( $2.03 \pm 0.13$ and $1.65 \pm 0.07$, respectively) when compared to Dox $(40 \mu \mathrm{M}$, both $p<0.05)$ (see Fig. $5 \mathrm{~B})$. Furthermore, MitoQ showed significantly better protective effects than SKQ1 at $1 \mu \mathrm{M}$ and $10 \mu \mathrm{M}$ (see Fig. 5B). 

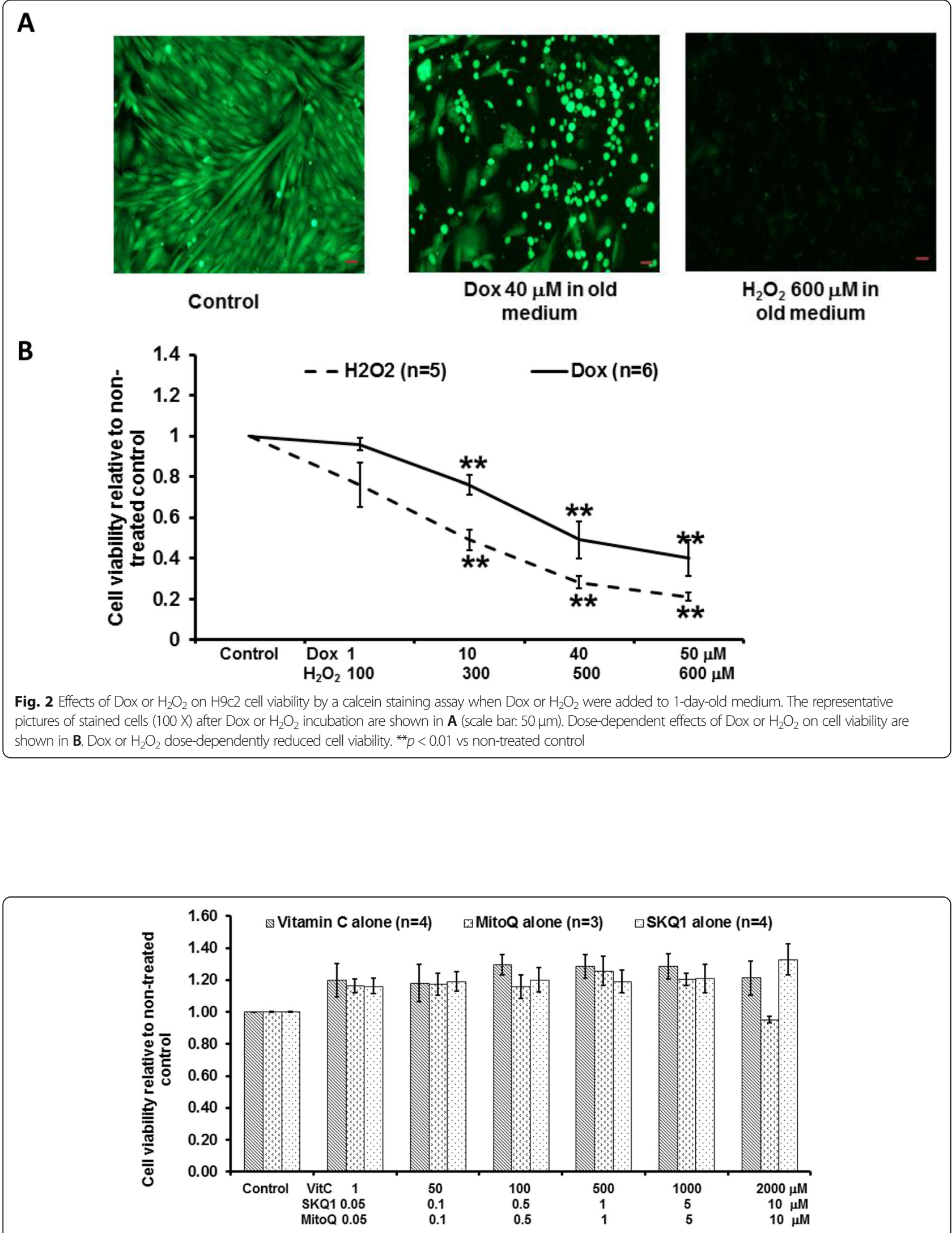

Fig. 3 The effects of vitamin C, MitoQ, or SKQ1 on cell viability. There was no significant change in cell viability by all the three antioxidants 
A

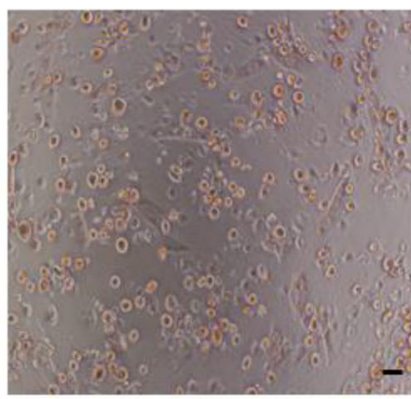

$\operatorname{Dox} 40 \mu \mathrm{M}$

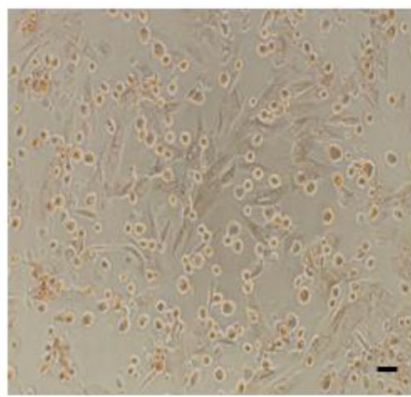

Dox $40 \mu \mathrm{M}+$ MitoQ $1 \mu \mathrm{M}$ co-treatment

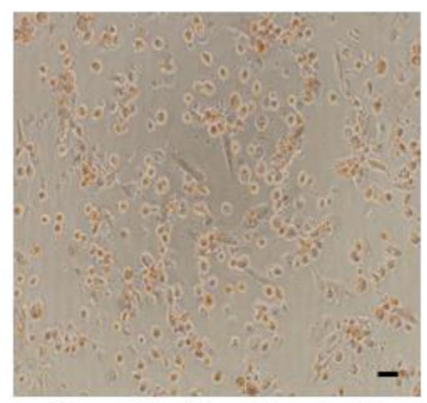

Dox $40 \mu \mathrm{M}+$ vitamin C $500 \mu \mathrm{M}$ co-treatment

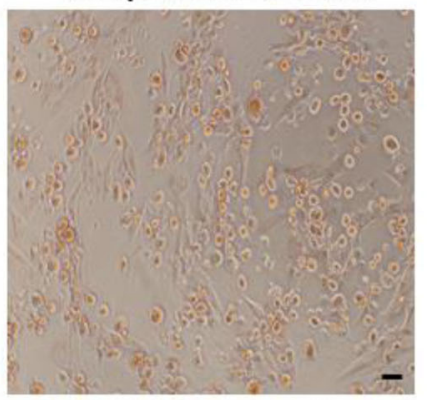

Dox $40 \mu \mathrm{M}+$ SKQ1 $1 \mu \mathrm{M}$ co-treatment

B

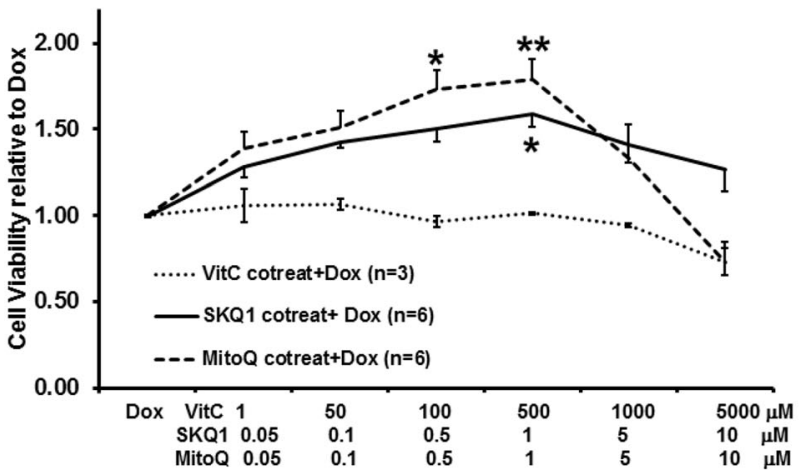

Fig. 4 The effects of vitamin C, MitoQ, or SKQ1 on cell viability against Dox when given as co-treatment. The representative pictures of cells (100 $\mathrm{X}$ ) after co-treatment are shown in $\mathbf{A}$ (scale bar: $50 \mu \mathrm{m}$ ). The effects of different antioxidants on Dox-induced cell damage are illustrated in $\mathbf{B}$. MitoQ and SKQ1, but not vitamin C, significantly increased cell viability in the presence of Dox. ${ }^{*} p<0.05$; ${ }^{*} p<0.01$ vs Dox

Furthermore, we found that intermediate doses of MitoQ $(0.05-0.5 \mu \mathrm{M})$ exerted better protection when given as co-treatment than pretreatment (see Fig. 6A-B). By contrast, higher doses of MitoQ $(1-10 \mu \mathrm{M})$ exerted better protection when given as pretreatment (see Fig. 6A). In particular, MitoQ $(2.5 \mu \mathrm{M}$ and $5 \mu \mathrm{M})$ pretreatment showed significantly higher cell viability $(2.19 \pm 0.13$ and $2.03 \pm 0.13)$ than co-treatment $(1.70 \pm$ 0.17 and $1.33 \pm 0.20$, see Fig. 6). Similarly, SKQ1 also showed better protection at intermediate doses (0.05$1 \mu \mathrm{M})$ when given as co-treatment. However, higher doses $(5 \mu \mathrm{M}$ and $10 \mu \mathrm{M})$ showed better effects when given as pretreatment. No significant differences were noticed among all the doses of SKQ1 between cotreatment and pretreatment (Fig. 6B).

\section{Dox significantly increased intracellular ROS and Mitochondrial so}

A key mechanism of Dox-induced cardiotoxicity is oxidative stress. The effects of Dox on intracellular ROS and mitochondrial $\mathrm{SO}$ are shown in Fig. 7A-B. We found that Dox $(1-50 \mu \mathrm{M}, n=3)$ increased intracellular ROS in a dose and time-dependent manner. We found that the non-treated control only slightly increased 


\section{A}

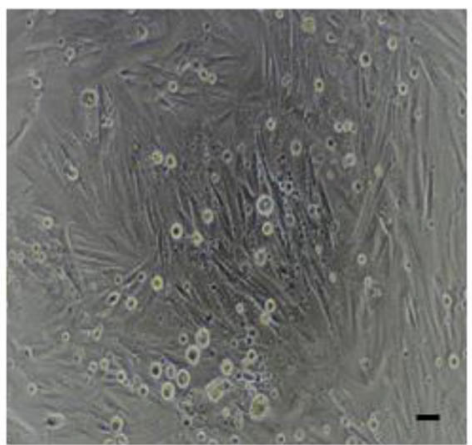

Control

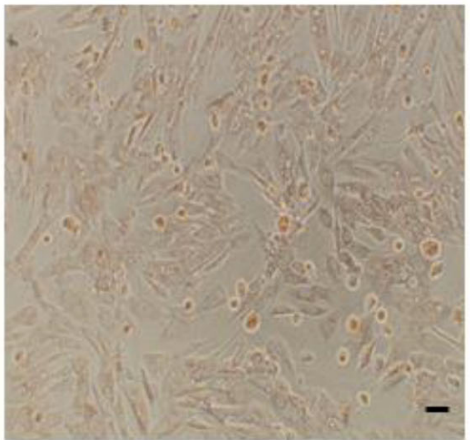

Dox $40 \mu \mathrm{M}+$ MitoQ $2.5 \mu$ M pretreatment

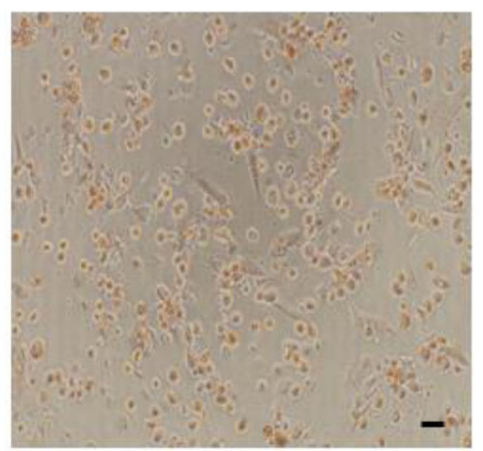

Dox $40 \mu \mathrm{M}$

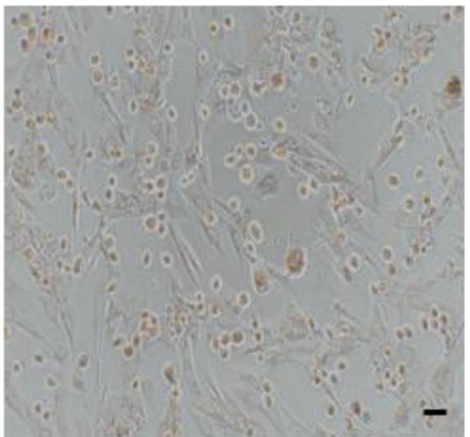

Dox $40 \mu \mathrm{M}+$ SKQ1 $5 \mu \mathrm{M}$ pretreatment

B

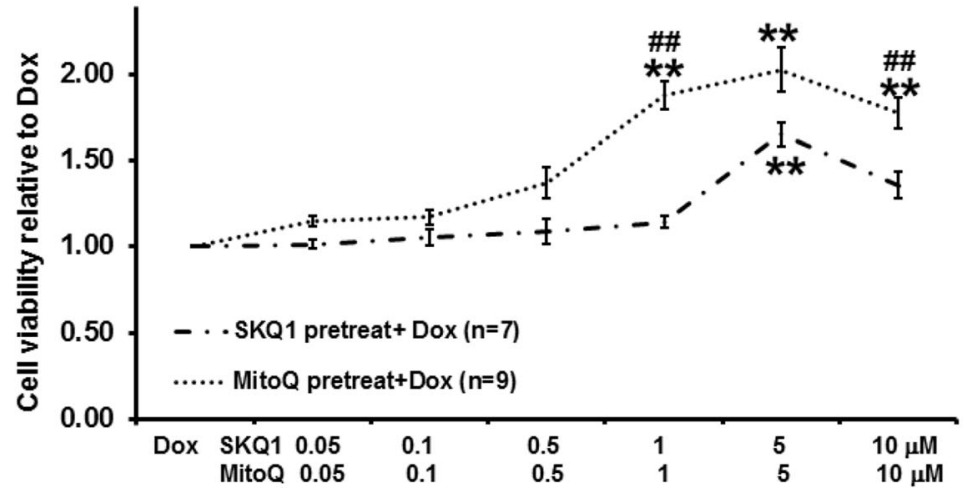

Fig. 5 The effects of pretreatment of MitoQ or SKQ1 on Dox-induced cell viability reduction. The representative pictures of cells (100 X) after pretreatment are shown in $\mathbf{A}$ (scale bar: $50 \mu \mathrm{m}$ ). The effects of MitoQ and SKQ1 pretreatment on Dox-induced cell damage are illustrated in B. Higher doses of MitoQ or SKQ1 significantly improved cell viability when given as pretreatment. Moreover, MitoQ exerted significantly higher protection than SKQ1. * $p<0.05 ;{ }^{* *} p<0.01$ vs Dox; \#\#p 0.01 vs SKQ1

intracellular ROS $(1.16 \pm 0.06)$ at $24 \mathrm{~h}$ when compared to its baseline. Dox $(40 \mu \mathrm{M})$ significantly increased intracellular ROS at $10 \mathrm{~min}$ to $1.61 \pm 0.04$ fold when compared to the non-treated control baseline. At $24 \mathrm{~h}$, Dox $(40 \mu \mathrm{M})$ significantly increased intracellular ROS to $4.87 \pm 0.34$ fold relative to the non-treated control baseline (see Fig. 7A).

Similarly, Dox $(1 \mu \mathrm{M}-50 \mu \mathrm{M}, n=4)$ increased mitochondrial SO in a dose-dependent manner. At $24 \mathrm{~h}$, Dox
$(40 \mu \mathrm{M})$ significantly increased mitochondrial $\mathrm{SO}$ to $5.37 \pm 0.21$ fold when compared to non-treated control (see Fig. 7B).

\section{MitoQ and SKQ1 reduced Dox-induced intracellular ROS} and mitochondrial SO

The effects of SKQ1 $(0.05-5 \mu \mathrm{M}, n=4)$ and MitoQ $(0.05-5 \mu \mathrm{M}, n=4)$ co-treatment or pretreatment on Dox-induced intracellular ROS levels at $24 \mathrm{~h}$ are 

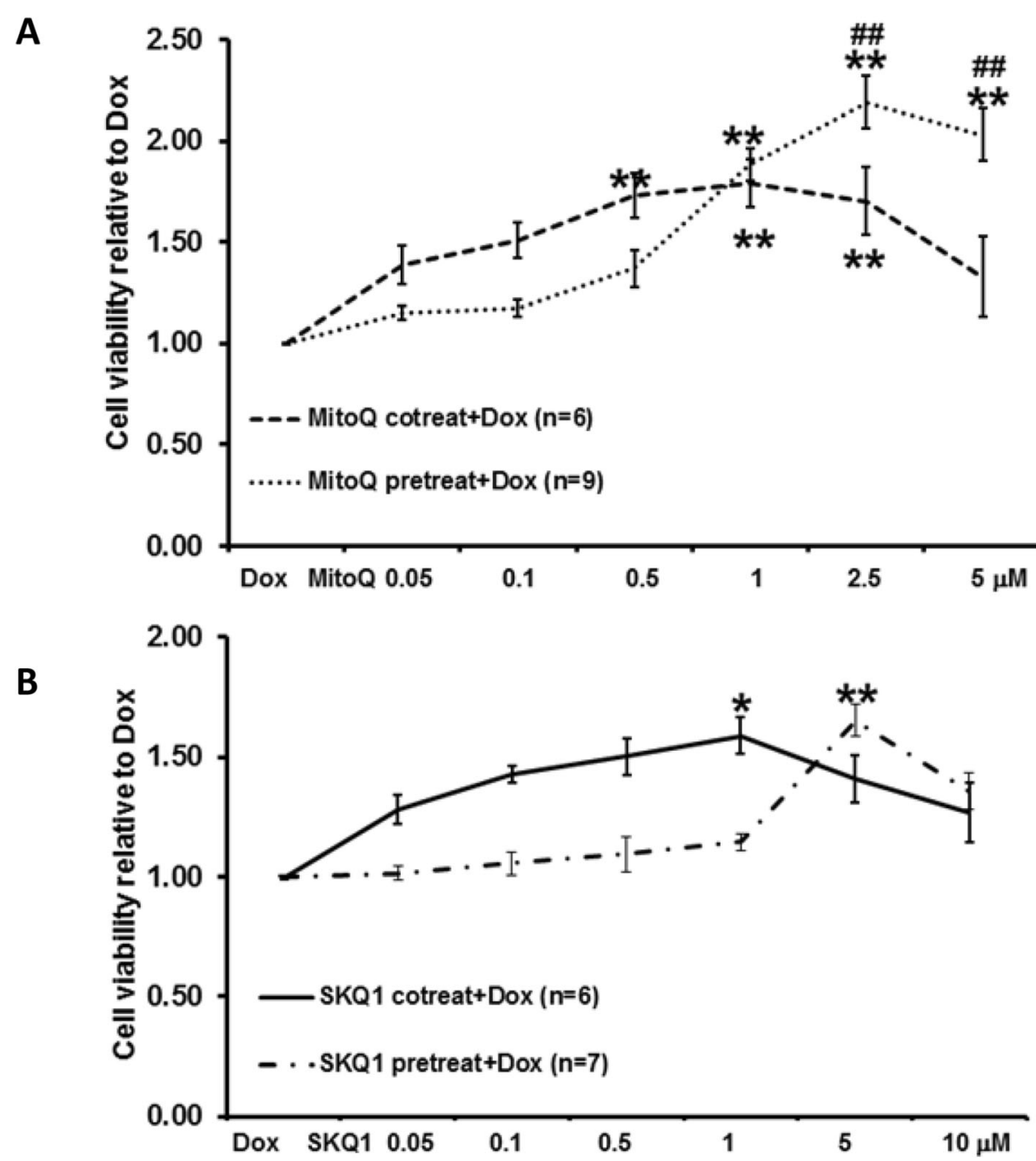

Fig. 6 The comparison between pretreatment and co-treatment of MitoQ (A) and SKQ1 (B) on Dox-induced cell damage. Pretreatment and cotreatment of MitoQ and SKQ1 significantly protected cells against Dox by demonstrating higher cell viability. Moreover, pretreatment of MitoQ, not SKQ1, exerted significantly higher protection than co-treatment at higher doses. ${ }^{*} p<0.05$; ${ }^{* *} p<0.01$ vs Dox; \#\#p $<0.01$ vs MitoQ co-treatment

illustrated in Fig. 8A-D. We found co-treatment or pretreatment of SKQ1 $(0.05-5 \mu \mathrm{M}, n=4)$ and MitoQ $(0.05-$ $5 \mu \mathrm{M}, n=4)$ significantly reduced Dox-induced intracellular ROS levels in a dose-dependent manner (all $p<$ $0.05)$. When given as co-treatment, intermediate dose $(1 \mu \mathrm{M})$ of SKQ1 and MitoQ showed maximal reduction of intracellular ROS levels to $0.63 \pm 0.03$ and $0.54 \pm 0.02$, respectively, when compared to Dox alone (see Fig. 8A). By contrast, when given as pretreatment, higher dose $(5 \mu \mathrm{M})$ of SKQ1 and MitoQ showed higher reduction of intracellular ROS levels to $0.60 \pm 0.03$ and $0.43 \pm 0.01$, respectively, when compared to Dox alone (see Fig. 8B). Both were significantly higher than the corresponding effects of $5 \mu \mathrm{M}$ of SKQ1 and MitoQ when administered as co-treatment (both $p<0.05$, see Fig. $8 \mathrm{C}-\mathrm{D}$ ). Moreover, only $0.5 \mu \mathrm{M}$ MitoQ co-treatment exhibited a significantly higher reduction in intracellular ROS levels when compared to $0.5 \mu \mathrm{M}$ SKQ1 $(p<0.05$, see Fig. 8A). By contrast, most doses $(0.05,0.5-5 \mu \mathrm{M})$ of MitoQ pretreatment exhibited a significantly higher reduction in intracellular ROS levels than SKQ1 pretreatment (all $p<$ 0.05, see Fig. 8B).

The effects of SKQ1 $(0.05-5 \mu \mathrm{M}, n=3)$ and MitoQ (0.05-5 $\mu \mathrm{M}, n=3-4)$ co-treatment or pretreatment on Dox-induced mitochondrial SO at $24 \mathrm{~h}$ are illustrated in Fig. 9A-D. Similarly, co-treatment or pretreatment of SKQ1 and MitoQ significantly reduced mitochondrial SO, although only pretreatment showed a dosedependent manner (see Fig. 9A-B). Moreover, cotreatment of SKQ1 and MitoQ showed better reduction on mitochondrial SO levels at lower dose range (0.05$1 \mu \mathrm{M})$, whereas pretreatment of both drugs showed 

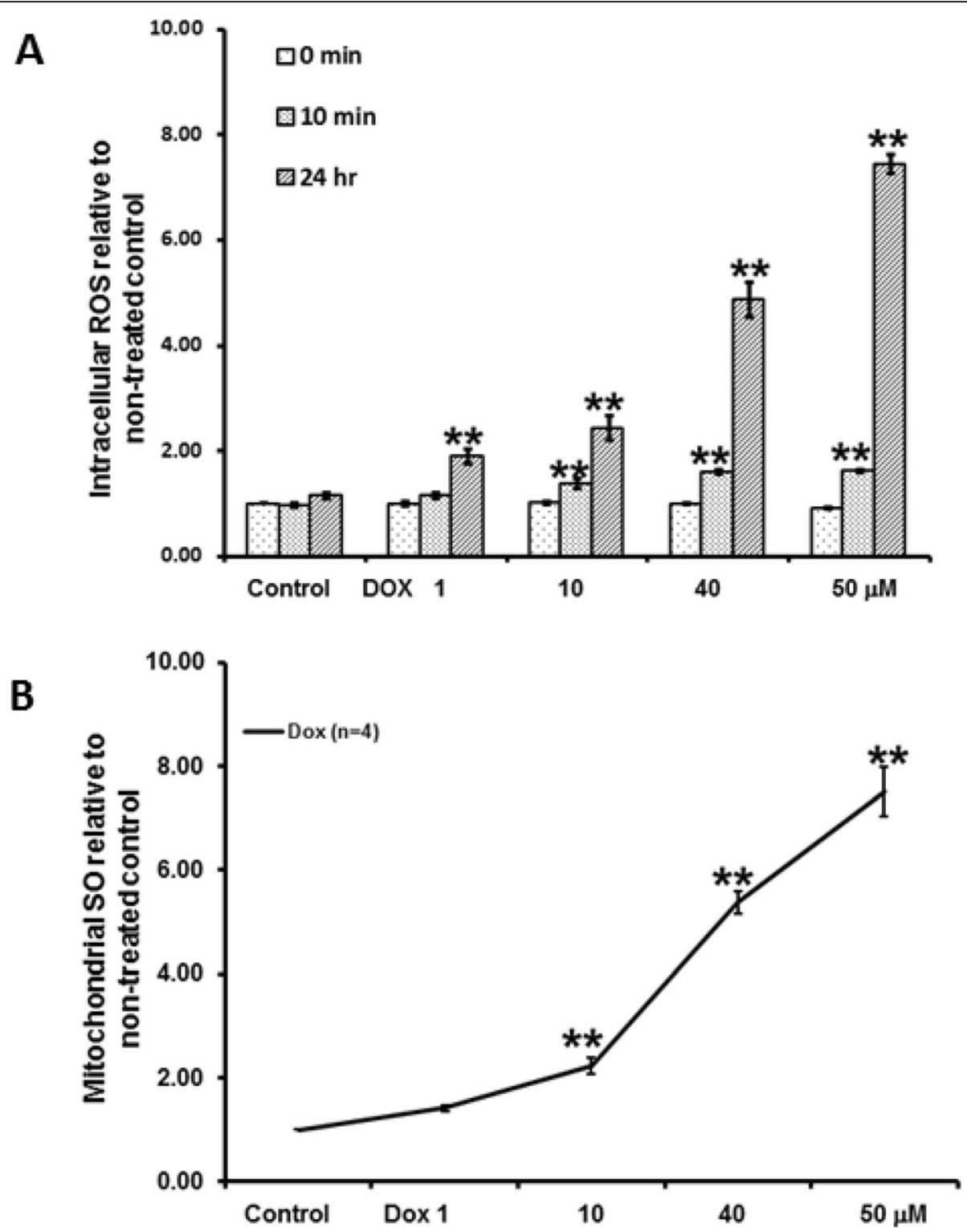

Fig. 7 The effects of Dox on intracellular ROS (A) and mitochondrial SO (B) levels. Dox showed dose-dependent increase in intracellular ROS and mitochondrial SO levels. ${ }^{*} P<0.01$ vs the non-treated control

better effects at higher dose range $(1-5 \mu \mathrm{M})$. Cotreatment of MitoQ $(5 \mu \mathrm{M})$ and SKQ1 $(5 \mu \mathrm{M})$ slightly reduced mitochondrial SO to $0.82 \pm 0.04$ and $0.82 \pm 0.16$, respectively, when compared to Dox alone. By contrast, pretreatment of MitoQ ( $5 \mu \mathrm{M})$ and SKQ1 $(5 \mu \mathrm{M})$ significantly reduced mitochondrial $\mathrm{SO}$ to $0.43 \pm 0.04$ and $0.43 \pm 0.05$, respectively, when compared to Dox alone (both $p<0.01$ ). Both were also significantly higher than the corresponding effects of $5 \mu \mathrm{M}$ of SKQ1 and MitoQ when administered as co-treatment (both $p<0.05$, see Fig. 9C-D). Although MitoQ exhibited better reductions in mitochondrial $\mathrm{SO}$ at most doses than SKQ1 when given as co-treatment or pretreatment, there were no significant differences.

\section{Discussion}

In summary, we found that Dox $(0.5-50 \mu \mathrm{M})$ dosedependently reduced $\mathrm{H} 9 \mathrm{c} 2$ cell viability. The effects were similar as those caused by a common oxidative stress inducer, $\mathrm{H}_{2} \mathrm{O}_{2}$. However, unlike $\mathrm{H}_{2} \mathrm{O}_{2}$, there was no difference in Dox cytotoxicity when Dox was added to a fresh medium or 1-day-old medium. Thereafter, we showed that mitochondrial targeted antioxidants, SKQ1or MitoQ, but not the common antioxidant, vitamin $\mathrm{C}$, significantly mitigated Dox-induced cell damage when given as cotreatment or pretreatment. Interestingly, pretreatment of MitoQ provided significantly higher efficacy of cell protection when compared to MitoQ co- treatment or SKQ1 pretreatment. Lastly, we demonstrated that Dox dose- 


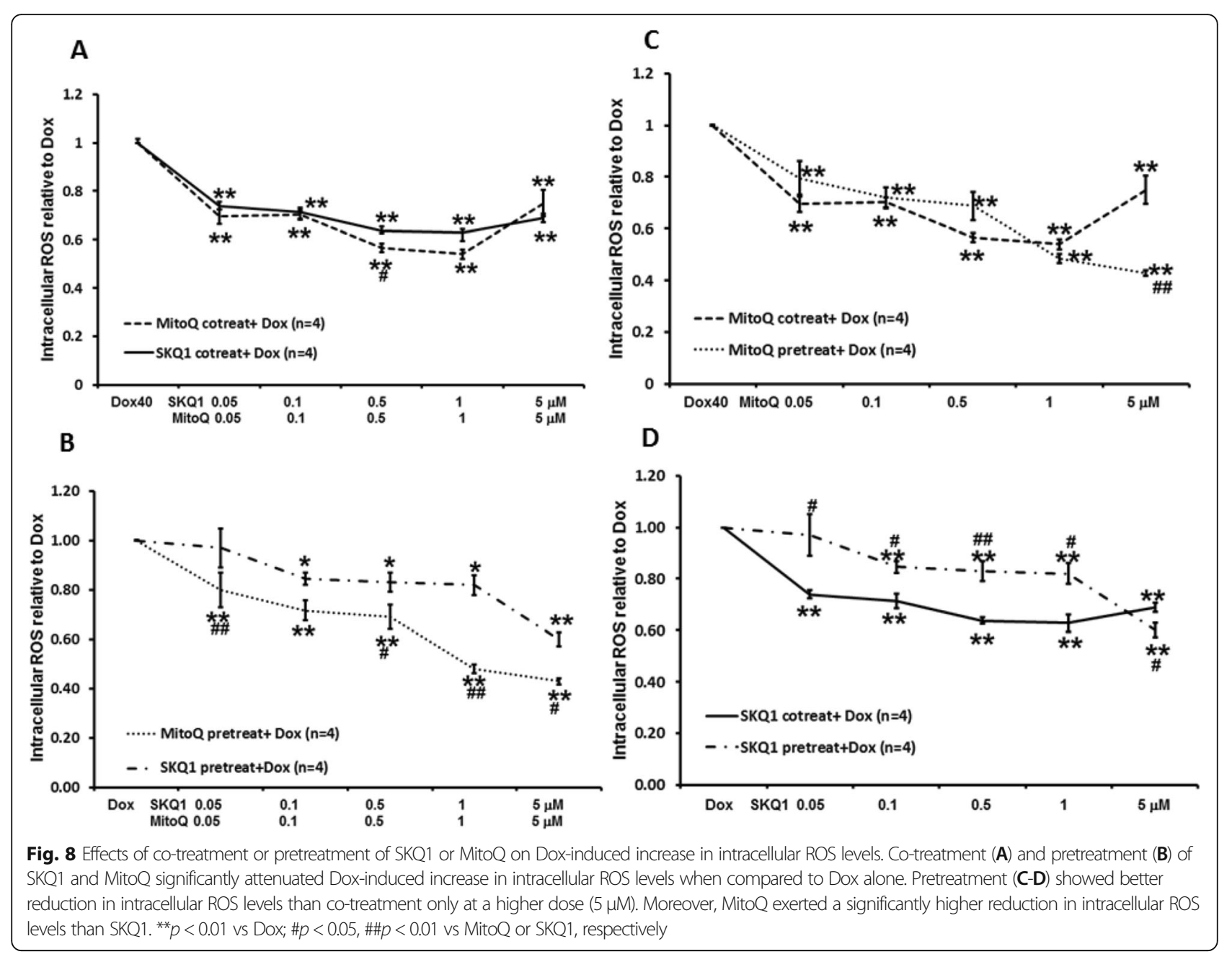

dependently increased intracellular ROS and mitochondrial SO. By contrast, co-treatment or pretreatment of SKQ1 or MitoQ significantly reduced Dox-induced intracellular ROS and mitochondrial SO. However, pretreatment shower higher reduction only at higher doses than co-treatment.

\section{Dox induced H9c2 cell damage by increasing intracellular and mitochondrial ROS}

Dox is a powerful chemotherapeutic drug and widely used in solid cancer treatment [19]. Dox usage is limited due to induction of irreversible cardiotoxicity $[1,20]$. This damage is characterized by cardiac cell apoptosis or necrosis which can lead to cardiomyopathy [21]. Our study showed that Dox $(0.5-50 \mu \mathrm{M})$ dose-dependently decreased $\mathrm{H} 9 \mathrm{c} 2$ myoblast cell viability after incubation for $24 \mathrm{~h}$. The cell viability was evaluated by measuring intracellular dehydrogenase activity of viable cells and confirmed by calcein staining. Our results are consistent with a study by Zhang et al. showing that Dox induced cell damage in a dose- and time-dependent manner. Dox
$(5 \mu \mathrm{M})$ caused about $30 \%$ reduction in $\mathrm{H} 9 \mathrm{c} 2$ cell viability after incubation for $24 \mathrm{~h}$ [20], which is similar to our data. By contrast, Dallons et al. showed Dox $(1-50 \mu \mathrm{M})$ had no effect on cell viability after incubation for $4 \mathrm{~h}$, whereas Dox $(1 \mu \mathrm{M})$ showed $60 \%$ reduction in cell viability after $24 \mathrm{~h}$ treatment when cell viability was measured by crystal violet assay [21]. The difference of Dox induced cell damage is possibly due to the sensitivity of methodology used to evaluate cell viability. Moreover, Dallons seeded cells at $3 \times 10^{4}$ cells $/ \mathrm{cm}^{2}$ and experiments started after cell seeding for $48 \mathrm{~h}$. By contrast, we seeded cells at $6 \times 10^{4}$ cells $/ \mathrm{cm}^{2}$ and experiments started after cell seeding for $24 \mathrm{~h}$. Researchers have found that cell numbers can influence cell damage effects induced by oxidizer [22].

In this study, we also showed that cell damage induced by $\mathrm{H}_{2} \mathrm{O}_{2}$ could be significantly impacted by fresh medium when compared to 1-day-old medium. The difference may be due to antioxidant effects provided by fetal bovine serum and $\alpha$-keto acid in fresh medium [23]. However, we did not see any significant difference 

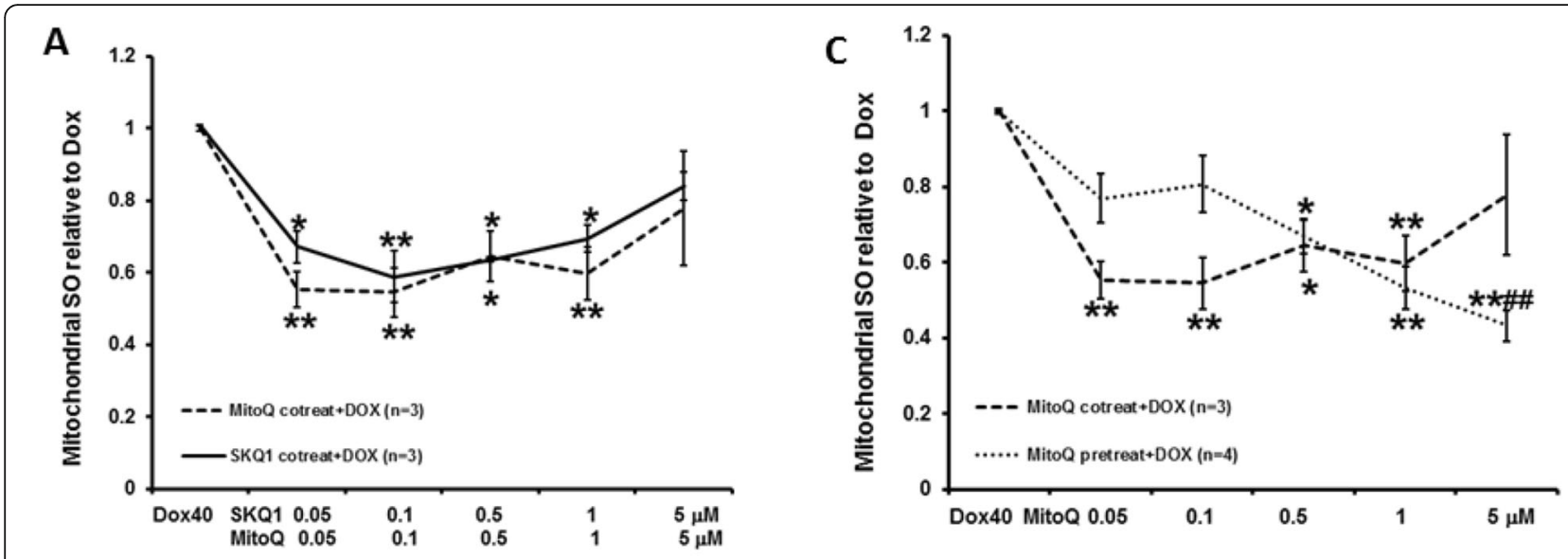

B
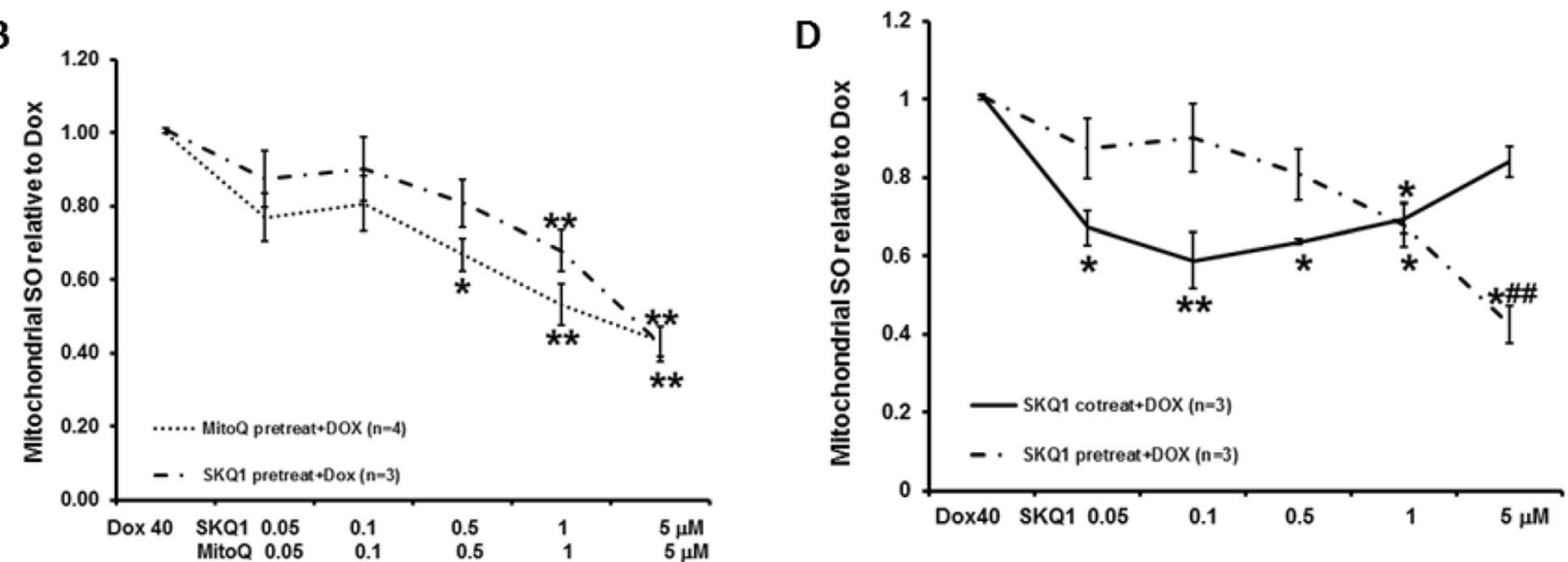

Fig. 9 Effects of co-treatment or pretreatment of SKQ1 or MitoQ on Dox-induced increase in mitochondrial SO levels. Co-treatment (A) or pretreatment (B) of SKQ1 and MitoQ significantly attenuated Dox-induced mitochondrial SO levels. Pretreatment (C-D) showed better reduction in mitochondrial SO levels than cotreatment only at a higher dose $(1-5 \mu \mathrm{M})$. Moreover, MitoQ exerted better reduction than SKQ1 at most doses. ${ }^{* *} p<0.01$ vs Dox; \#p $<0.05$, \#\#p $<0.01$ vs MitoQ or SKQ1, respectively

in cell viability by Dox between fresh medium and 1day-old medium. Therefore, we could add Dox into the fresh medium after washing out MitQ or SKQ1 after both drugs were given as pretreatment.

Oxidative stress is a major mechanism mediating Doxinduced cardiac damage. It has been found that Dox, a cationic compound, can accumulate in mitochondria 100 times more than in the cytosol due to larger mitochondrial membrane potential (e.g., -160 to $-180 \mathrm{mV}$ ). Moreover, Dox interacts with cardiolipin forming electrostatic bonds and disrupting the mitochondrial electron transport chain, particularly complex I and II [24]. In consequence, the dysfunctional electron transport chain facilitates SO generation and overwhelms the mitochondrial antioxidant capacity in the heart. Meanwhile, Dox itself undergoes redox cycling and directly reduces to a semiquinone species through interaction with complex I. This reduced semiquinone version of Dox can oxidize oxygen and form SO. Additionally, Dox can regulate mitochondrial NADPH oxidase increasing ROS production [25]. In this study, we found that Dox increased intracellular ROS in a dose and time-dependent manner. Intracellular ROS measured by DCF fluorescence intensity started to increase after Dox incubation for $10 \mathrm{~min}$ and it continued to rise until $24 \mathrm{~h}$. Moreover, we specifically measured mitochondrial $\mathrm{SO}$ levels by MitoSOX after Dox incubation for $24 \mathrm{~h}$. We found that the dose-response of Dox-induced mitochondrial SO increase was very similar as the dose-response of Doxinduced intracellular ROS increase at $24 \mathrm{~h}$. The data is consistent with Kuznetsov et al. showing Dox increased intracellular ROS evaluated by measuring DCF fluorescence intensity paralleled with mitochondrial redox state and membrane potential [26]. Asensio-Lopez et al. also showed that Dox dose and time-dependently increased intracellular ROS. Moreover, by utilizing MitoTracker green to locate mitochondria, they found that Dox started to appear in mitochondria at $15 \mathrm{~min}$ after administration. It was accompanied with increased ROS fluorescence at mitochondria as well. Both intensities 
increased as a function of time [25]. In consequence, increased ROS levels in mitochondria lead to membrane potential collapse, ATP production decrease, lipid peroxidation, cytochrome $\mathrm{C}$ release and mitochondrial DNA damage $[1,20]$. A large amount studies have confirmed that Dox induces apoptosis in cardiomyocytes by increasing cytochrome $\mathrm{C}$ and caspase 3 and 9 activity [1, $20,21]$.

\section{Vitamin C failed to protect cells against Dox-induced damage}

Because oxidative stress is a major and early event after giving Dox, there are numerous researchers investigating if antioxidants can protect the heart against Doxinduced cardiotoxicity. Most preclinical studies found that common antioxidants, such as vitamin $\mathrm{C}$, can protect the heart against Dox. Viswanatha Swamy et al. showed that vitamin C ( $20 \mathrm{mg} / \mathrm{kg}$ orally) when given 15 days before or 15 days after Dox significantly reduced heart cell damage and oxidative stress by enhancing antioxidant enzymes (e.g., superoxide dismutase, catalase) in rats [27]. Similarly, Akolkar et al. demonstrated better cardiac structure and function in rats when vitamin C (50 mg/kg, orally) was given a week before and continued till 2 weeks after Dox injection. Moreover, they illustrated vitamin $C$ significantly mitigated Doxinduced nitrosative stress, proapoptotic proteins (e.g., caspase 3), inflammatory cytokines (e.g., interleukin 6), and the relevant signaling proteins (e.g., p53, nuclear factor kappa light chain enhancer of activated B cells, autophagy) in rats and isolated cardiomyocytes [5, 8, 28]. However, it is still a lack of sufficient clinical research evidence to prove the effectiveness of vitamin $C$ in the attenuation of cardiotoxicity caused by Dox [29, 30].

In this study, we expected that vitamin $C$ would mitigate Dox-induced cell damage. Moreover, it could serve as an effective control to compare mitochondrialtargeted antioxidants' effects. We first found that vitamin C $(1-2000 \mu \mathrm{M})$ alone only slightly increased cell viability after incubation for $24 \mathrm{~h}$. However, when vitamin $C(1-2000 \mu \mathrm{M})$ was applied concurrently with Dox, vitamin $C$ failed to show any protective effects. Moreover, higher doses of vitamin $C(1000 \mu \mathrm{M}$ and $2000 \mu \mathrm{M})$ showed slightly lower cell viability than Dox alone. So far, vitamin $C$ has not shown any protection against Dox-induced cardiotoxicity in clinical studies [29, 30]. This may be because vitamin $C$ is not able to reach sources of ROS (e.g. mitochondria) quickly enough to scavenge ROS or its potential pro-oxidant property. Vitamin $C$ is hydrophilic and it gets into the cell or cellular organelles by $\mathrm{Na}$-dependent vitamin $\mathrm{C}$ transporter or glucose transporter. AKolkar et al. showed that Dox downregulated the expression of both transporter proteins in the cardiomyocytes [8]. Moreover, the distributions of vitamin $\mathrm{C}$ in different intracellular compartments vary in different tissues. For example, vitamin $\mathrm{C}$ concentration is five times less in the mitochondria of mouse skeletal muscle than that in the liver [31]. Furthermore, studies indicate that vitamin $\mathrm{C}$ can become pro-oxidant at higher concentration (e.g., > $1000 \mu \mathrm{M}$ ), higher intracellular transition metal ions, or dysfunctional mitochondria [32-34]. In addition, a higher Dox concentration (e.g., $40 \mu \mathrm{M}$ ) was used in this study than other studies (e.g., $10 \mu \mathrm{M})$. All the above factors may contribute to why vitamin $\mathrm{C}$ showed no cell protection against Dox in this study.

\section{MitoQ and SKQ1, given as pretreatment, mitigated Dox- induced cell damage at higher degree than co-treatment} Due to Dox mainly accumulating in the mitochondria to induce oxidative stress, mitochondrial-targeted antioxidants would be more efficient to mitigate Dox-induced cell damage. MitoQ and SKQ1 are two well-studied mitochondrial-targeted antioxidants [35]. They are ubiquinone and plastoquinone, respectively, conjugated to a TPP, a lipophilic cation. The conjugated drugs accumulate several hundred times more in the mitochondria than cytosol due to larger membrane potential within the cell $[10,36]$. Inside mitochondria, MitoQ and SKQ1 switch between their reduced and oxidized form via the electron transport chain, with the reduced form able to scavenge ROS [15, 37]. However, MitoQ and SKQ1 can be pro-oxidants at higher doses [15]. We found that MitoQ (0.05-5 $\mu \mathrm{M})$ and SKQ1 (0.05-10 $\mu \mathrm{M})$ alone slightly increased cell viability when compared to nontreated control. By contrast, a higher dose of MitoQ $(10 \mu \mathrm{M})$ slightly reduced $\mathrm{H} 9 \mathrm{c} 2$ cell viability by $5 \%$. Mendez et al. also showed that MitoQ $(10 \mu \mathrm{M})$ is cytotoxic to platelets [38].

It is well-known that heart preconditioning by transient ischemia/reperfusion episodes allows the heart develop resilience to endure a harsher insult, such as prolonged ischemia/reperfusion injury [39]. Currently, this strategy has been tried to mitigate Dox-induced cardiotoxicity. Maulik et al. showed that simulated preconditioning by hypoxia/reoxygenation attenuated Doxinduced cell damage in primary adult cardiac myocytes. However, a ROS scavenger, $\mathrm{N}$-acetyl cysteine, failed to show any protection when given concurrently with Dox [16]. Similarly, Galan-Arriola et al. found that remote ischemia preconditioning before intracoronary injection of Dox preserved significantly better left ventricular ejection fraction, mitochondrial morphology, and DNA copies in pigs' heart [17]. Instead of using ischemic preconditioning, we pretreated cells with mitochondrial targeted antioxidants, MitoQ or SKQ1, 24 h prior to Dox in this study. We also compared the effects of pretreatment to those of co-treatment. We found both co- 
treatment and pretreatment mitigated Dox-induced cell damage in $\mathrm{H} 9 \mathrm{c} 2$ myoblast cells. However, the doseresponses were different between co-treatment and pretreatment. Co-treatment showed significant protection at intermediate doses of MitoQ $(0.5-1 \mu \mathrm{M})$ and SKQ1 $(1 \mu \mathrm{M})$; whereas higher doses showed reduced protection. By contrast, when given as pretreatment, higher doses of MitoQ $(1-10 \mu \mathrm{M})$ and SKQ1 $(5 \mu \mathrm{M})$ were required to protect the cells against Dox. Moreover, the efficacy of protection by MitoQ pretreatment was significantly better than its co-treatment. We further found that the protection may be related to the dosedependent reduction in intracellular ROS and mitochondrial SO. It is noticeable that both drug's antioxidant effects shared the similar shift of dose-dependent response between co-treatment and pretreatment. To our knowledge, the present study showed that pretreatment of mitochondrial-targeted antioxidants has higher efficacy against Dox-induced cell damage than co-treatment for the first time. The difference possibly is due to the following reasons: 1 . Accumulation of MitoQ or SKQ1 in mitochondria depends on mitochondrial membrane potential [10]. When the drugs were co-administered with Dox, Dox dissipated the mitochondrial membrane potential which possibly reduced the drug accumulation in mitochondria; 2. It has been reported that higher doses of MitoQ and SKQ1 can be prooxidants. In particular, MitoQ shows higher pro-oxidant property at lower doses than SKQ1 in vitro studies [13]. Moreover, Huang et al. found that MitoQ $(10 \mu \mathrm{M})$ reduced mitochondrial membrane potential in pancreatic acinar cells [40]. We found that higher doses of SKQ1 or MitoQ (e.g. 5 and $10 \mu \mathrm{M})$ when given as co-treatment showed less cell protection or no protection at all. 3. MitoQ/SKQ1 and Dox exert effects via the electron transport chain and cardiolipin, which may lead to interference when given at the same time. For example, Dox needs to be converted to semiquinone causing ROS increase by complex I. By contrast, MitoQ relies on complex I and II to recycle between the reduced and oxidized forms [41]. Similarly, SKQ1 recharges itself between reduced and oxidized forms via complex II and complex III [37]. Furthermore, Dox and SKQ1 showed higher affinity for mitochondrial cardiolipin than MitoQ. However, Dox binding disrupts cardiolipin whereas SKQ1or MitoQ protects cardiolipin from oxidation to preserve mitochondria's normal function $[24,42]$. By contrast, when MitoQ or SKQ1 was applied before Dox, drug accumulation into mitochondria and the antioxidant capacity was unlikely influenced. All the above presumptions warrant further investigation to support that pretreatment would be a better strategy when giving mitochondrial-targeted antioxidants.

Additionally, we demonstrated that MitoQ exhibited significantly higher efficacy against Dox than SKQ1 when both were given as pretreatment. The cellular protection may be partially related to its higher reduction on intracellular ROS and mitochondrial SO than SKQ1 as our data suggested. Plenty of studies support the concept that MitoQ can mitigate Dox-induced cardiotoxicity by reducing oxidative stress $[1,13]$. By contrast, SKQ1 has not been widely studied in Dox-induced cardiotoxicity. However, it has been used in eye drops as a defense against oxidative stress due to dry eye syndrome [43]. SKQ1 has been also studied to promote survival of kidney epithelial cells and significantly improved survival of rats subjected to ischemia/reperfusion injury by reducing oxidative stress [44]. In vitro studies suggest that SKQ1 has antioxidant effects at lower concentrations than MitoQ [13]. Moreover, the reduced form of SKQ1 has a four-fold higher decrease in peroxyl radicals than the reduced form of MitoQ [11]. In addition to their antioxidant ability, $\mathrm{Hu}$ et al. recently indicated that MitoQ pretreatment activated Nrf2 signaling to enhance antioxidant capacity and to protect mitochondrial DNA in an intestinal ischemia/reperfusion model [18]. The role of Nrf2 signaling in cardioprotection provided by pretreatment of MitoQ or SKQ1 needs to be further elucidated.

\section{Limitation}

We acknowledge that this study was performed on a rat H9c2 cardiomyoblast cell line instead of primary cultured cardiomyocytes. However, Kuznetsov et al. compared H9c2 cells' mitochondrial biogenesis, function and response to hypoxia/reoxygenation to primary cardiomyocytes'. They suggested that $\mathrm{H} 9 \mathrm{c} 2$ cells were very similar to primary heart cells regarding the energy metabolism and mitochondrial properties [45]. Therefore, we would like to further validate the effects of pretreatment of mitochondrial-targeted antioxidants in a Doxinduced cardiotoxicity animal model. Moreover, we did not evaluate whether Dox's anti-cancer effects would be compromised by using mitochondrial-targeted antioxidants as co-treatment or pretreatment. Rao et al. demonstrated that MitoQ exerted 30 times more cytotoxicity to breast cancer cell lines than to healthy mammary epithelial cells [46]. Moreover, they also found that MitoQ not only increased Dox's anti-cancer effects but also mitigated Dox-induced cardiotoxicity [47]. Similarly, SKQ1 also showed to attenuate cell growth in fibrosarcoma and rhabdomyosarcoma tumor cell lines and related animal models [48]. However, given the possibility of competition when mitochondrial-targeted antioxidants are co-treated with Dox, it will be very intriguing to find out if administration of MitoQ or SKQ1 as pretreatment prior to Dox would provide better anti-cancer effects than co-treatment. It will also shine some light on how 
cancer patients can safely take antioxidants and not interfere with anti-cancer treatments' benefits.

\section{Conclusion}

This present study showed that Dox dose-dependently reduced cell viability of $\mathrm{H} 9 \mathrm{c} 2$ cells by increasing intracellular ROS and mitochondrial SO. Mitochondrial targeted antioxidants, MitoQ and SKQl, but not vitamin C, significantly mitigated Dox-induced cell damage when given as co-treatment or pretreatment. Interestingly, MitoQ pretreatment showed significantly higher efficacy in cellular protection than MitoQ co-treatment and SKQ1 pretreatment. The protective effects by MitoQ and SKQ1 were associated with significant reduction in intracellular ROS and mitochondrial SO. The data also demonstrate that pretreating cardiomyocytes by MitoQ prior to Dox may exert significantly better cardioprotection than co-treatment. The mechanisms underlying the difference between co-treatment and pretreatment against Dox-induced cardiac cell damage and the impacts on Dox's anti-cancer effects will be explored in future studies.

\author{
Abbreviations \\ Dox: Doxorubicin; TOP II: Topoisomerase II; ROS: Reactive oxygen species; \\ MitoQ: Mitoquinone; SKQ1: 10-(6'-plastoquinonyl) \\ decyltriphenylphosphonium; TPP: Decyl-triphenylphosphonium; \\ ATCC: American Type Culture Collection; $\mathrm{H}_{2} \mathrm{O}_{2}$ : Hydrogen peroxide; CCK- \\ 8: Cell counting kit-8; DCFDA: 2, 7-dichlorofluorescin diacetate; \\ SO: Superoxide
}

\section{Acknowledgements}

The study was supported by Division of Research and Department of BioMedical Sciences at PCOM.

\begin{abstract}
Authors' contributions
All authors contributed to completion of the study and manuscript. Research design, material preparation, data collection, and analysis were performed by $H O, B S, R M, A S, C W, H A, E R, A P, S P, R B, L Y$, and QC. The first draft of the manuscript was written by BS and QC. References citation was completed by AH. All authors commented on previous versions of the manuscript and approved the final manuscript. The whole process was supervised by QC. All data were generated in-house and no paper mill was used.
\end{abstract}

\section{Authors' information}

All authors are affiliated with Philadelphia College of Osteopathic Medicine, 4170 City Avenue, Philadelphia, PA 19131.

\section{Funding}

The research was supported by Division of Research and Department of BioMedical Sciences at Philadelphia College of Osteopathic Medicine. The funding bodies played no role in the design of the study and collection, analysis, and interpretation of data and in writing the manuscript.

\section{Availability of data and materials}

The datasets generated during and/or analyzed during the current study are available from the corresponding author on reasonable request.

\section{Declarations}

\section{Ethics approval and consent to participate}

This is an observational study using a non-human cell line. The Philadelphia College of Osteopathic Medicine Research Ethics Committee has confirmed that no ethical approval is required. The consent to participate is not applicable for the study.

\section{Consent for publication}

Not Applicable.

\section{Competing interests}

The authors have no relevant financial or non-financial interests to disclose. Moreover, the authors have no conflicts of interest to declare that are relevant to the content of this article. Additionally, all authors certify that they have no affiliations with or involvement in any organization or entity with any financial interest or non-financial interest in the subject matter or materials discussed in this manuscript. Lastly, the authors have no financial or proprietary interests in any material discussed in this article.

Received: 6 April 2021 Accepted: 3 September 2021

Published online: 16 September 2021

\section{References}

1. Santos DSd, Goldenberg RCdS. Doxorubicin-induced cardiotoxicity: from mechanisms to development of efficient therapy; 2018. https://doi.org/10. 5772/intechopen.79588.

2. Wenningmann N, Knapp M, Ande A, Vaidya TR, Ait-Oudhia S. Insights into doxorubicin-induced cardiotoxicity: molecular mechanisms, preventive strategies, and early monitoring. Mol Pharmacol. 2019;96(2):219-32. https:// doi.org/10.1124/mol.119.115725.

3. Varghese SS, Eekhoudt CR, Jassal DS. Mechanisms of anthracycline-mediated cardiotoxicity and preventative strategies in women with breast cancer. Mol Cell Biochem. 2021;476(8):3099-109. https://doi.org/10.1007/s11010-021-04152-y.

4. Cappetta D, de Angelis A, Sapio L, Prezioso L, Illiano M, Quaini F, et al. Oxidative stress and cellular response to doxorubicin: a common factor in the complex milieu of anthracycline cardiotoxicity. Oxidative Med Cell Longev. 2017;2017:1521020-13. https://doi.org/10.1155/2017/1521020.

5. Varela-López A, Battino M, Navarro-Hortal MD, Giampieri F, ForbesHernández TY, Romero-Márquez JM, et al. An update on the mechanisms related to cell death and toxicity of doxorubicin and the protective role of nutrients. Food Chem Toxicol. 2019;134:110834. https://doi.org/10.1016/j. fct.2019.110834

6. Yin J, Guo J, Zhang Q, Cui L, Zhang L, Zhang T, et al. Doxorubicin-induced mitophagy and mitochondrial damage is associated with dysregulation of the PINK1/parkin pathway. Toxicol in Vitro. 2018;51:1-10. https://doi.org/10.1 016/j.tiv.2018.05.001.

7. Songbo $M$, Lang $H$, Xinyong $C$, Bin $X$, Ping Z, Liang S. Oxidative stress injury in doxorubicin-induced cardiotoxicity. Toxicol Lett. 2019;307:41-8. https:// doi.org/10.1016/j.toxlet.2019.02.013.

8. Akolkar G, da Silva Dias D, Ayyappan P, Bagchi AK, Jassal DS, Salemi VMC, et al. Vitamin C mitigates oxidative/nitrosative stress and inflammation in doxorubicin-induced cardiomyopathy. Am J Physiol Heart Circ Physiol. 2017; 313(4):H795-809. https://doi.org/10.1152/ajpheart.00253.2017.

9. Pawlowska E, Szczepanska J, Blasiak J. Pro- and antioxidant effects of vitamin $\mathrm{C}$ in cancer in correspondence to its dietary and pharmacological concentrations. Oxidative Med Cell Longev. 2019;2019:7286737-18. https:// doi.org/10.1155/2019/7286737.

10. Zinovkin RA, Zamyatnin AA. Mitochondria-targeted drugs. Curr Mol Pharmacol. 2019;12(3):202-14. https://doi.org/10.2174/187446721266618112 7151059.

11. Antonenko YN, Avetisyan AV, Bakeeva LE, Chernyak BV, Chertkov VA, Domnina LV, et al. Mitochondria-targeted plastoquinone derivatives as tools to interrupt execution of the aging program. 1. Cationic plastoquinone derivatives: synthesis and in vitro studies. Biochemistry (Mosc). 2008;73(12): 1273-87. https://doi.org/10.1134/s0006297908120018.

12. Cui L, Zhou Q, Zheng X, Sun B, Zhao S. Mitoquinone attenuates vascular calcification by suppressing oxidative stress and reducing apoptosis of vascular smooth muscle cells via the Keap1/Nrf2 pathway. Free Radic Biol Med. 2020;161:23-31. https://doi.org/10.1016/j.freeradbiomed.2020.09.028.

13. Chandran K, Aggarwal D, Migrino RQ, Joseph J, McAllister D, Konorev EA, et al. Doxorubicin inactivates myocardial cytochrome c oxidase in rats: cardioprotection by Mito-Q. Biophys J. 2009;96(4):1388-98. https://doi.org/1 0.1016/j.bpj.2008.10.042.

14. Skulachev VP, Antonenko YN, Cherepanov DA, Chernyak BV, Izyumov DS, Khailova $L S$, et al. Prevention of cardiolipin oxidation and fatty acid cycling 
as two antioxidant mechanisms of cationic derivatives of plastoquinone (SkQs). Biochim Biophys Acta. 2010;1797(6-7):878-89. https://doi.org/10.101 6/j.bbabio.2010.03.015.

15. Williamson J, Davison G. Targeted antioxidants in exercise-induced mitochondrial oxidative stress: emphasis on DNA damage. Antioxidants (Basel). 2020;9(11). https://doi.org/10.3390/antiox9111142.

16. Maulik A, Davidson SM, Piotrowska I, Walker M, Yellon DM. Ischaemic preconditioning protects cardiomyocytes from anthracycline-induced toxicity via the PI3K pathway. Cardiovasc Drugs Ther. 2018;32(3):245-53. https://doi.org/10.1007/s10557-018-6793-y.

17. Galan-Arriola C, et al. Remote ischemic preconditioning ameliorates anthracycline-induced cardiotoxicity and preserves mitochondrial integrity. Cardiovasc Res. 2020;117(4):1132-43. https://doi.org/10.1093/cvr/cvaa181.

18. Hu Q, Ren J, Li G, Wu J, Wu X, Wang G, et al. The mitochondrially targeted antioxidant MitoQ protects the intestinal barrier by ameliorating mitochondrial DNA damage via the Nrf2/ARE signaling pathway. Cell Death Dis. 2018;9(3):403. https://doi.org/10.1038/s41419-018-0436-X.

19. Sritharan S, Sivalingam N. A comprehensive review on time-tested anticancer drug doxorubicin. Life Sci. 2021;278:119527. https://doi.org/10.1 016/j.lfs.2021.119527.

20. Zhang X, Li J, Cheng Y, Yi J, Liu X, Cheng W. Downregulation of CUEDC2 prevents doxorubicininduced cardiotoxicity in H9c2 cells. Mol Med Rep. 2018;18:855-63. https://doi.org/10.3892/mmr.2018.9072.

21. Dallons M, Schepkens C, Dupuis A, Tagliatti V, Colet JM. New insights about doxorubicin-induced toxicity to cardiomyoblast-derived H9C2 cells and dexrazoxane cytoprotective effect: contribution of in vitro (1)H-NMR metabonomics. Front Pharmacol. 2020;11:79. https://doi.org/10.3389/fphar.2 020.00079 .

22. Gulden M, et al. Cytotoxic potency of $\mathrm{H}_{2} \mathrm{O} 2$ in cell cultures: impact of cell concentration and exposure time. Free Radic Biol Med. 2010;49(8):1298-305. https://doi.org/10.1016/j.freeradbiomed.2010.07.015.

23. Gum ET, Swanson RA, Alano C, Liu J, Hong S, Weinstein PR, et al. Human serum albumin and its N-terminal tetrapeptide (DAHK) block oxidantinduced neuronal death. Stroke. 2004;35(2):590-5. https://doi.org/10.1161/ 01.STR.0000110790.05859.DA.

24. Gorini S, de Angelis A, Berrino L, Malara N, Rosano G, Ferraro E. Chemotherapeutic drugs and mitochondrial dysfunction: focus on doxorubicin, trastuzumab, and sunitinib. Oxidative Med Cell Longev. 2018; 2018:7582730-15. https://doi.org/10.1155/2018/7582730.

25. Asensio-Lopez MC, et al. Early oxidative damage induced by doxorubicin: source of production, protection by GKT137831 and effect on $\mathrm{Ca}(2+)$ transporters in HL-1 cardiomyocytes. Arch Biochem Biophys. 2016;594:2636. https://doi.org/10.1016/j.abb.2016.02.021

26. Kuznetsov AV, Margreiter R, Amberger A, Saks V, Grimm M. Changes in mitochondrial redox state, membrane potential and calcium precede mitochondrial dysfunction in doxorubicin-induced cell death. Biochim Biophys Acta. 2011;1813(6):1144-52. https://doi.org/10.1016/j.bbamcr.2011. 03.002 .

27. Viswanatha Swamy AH, et al. Cardioprotective effect of ascorbic acid on doxorubicin-induced myocardial toxicity in rats. Indian J Pharm. 2011;43(5): 507-11. https://doi.org/10.4103/0253-7613.84952.

28. Ludke A, Akolkar G, Ayyappan P, Sharma AK, Singal PK. Time course of changes in oxidative stress and stress-induced proteins in cardiomyocytes exposed to doxorubicin and prevention by vitamin C. PLoS One. 2017;12(7): e0179452. https://doi.org/10.1371/journal.pone.0179452.

29. Carr AC, Cook J. Intravenous vitamin C for cancer therapy - identifying the current gaps in our knowledge. Front Physiol. 2018;9:1182. https://doi.org/1 0.3389/fphys.2018.01182.

30. van Gorkom GNY, Lookermans EL, van Elssen CHMJ, Bos GMJ. The effect of vitamin C (ascorbic acid) in the treatment of patients with cancer: a systematic review. Nutrients. 2019;11(5). https://doi.org/10.3390/nu11050977.

31. Cantoni O, Guidarelli A, Fiorani M. Mitochondrial uptake and accumulation of vitamin C: what can we learn from cell culture studies? Antioxid Redox Signal. 2018;29(15):1502-15. https://doi.org/10.1089/ars.2017.7253.

32. Antunes LM, Takahashi CS. Protection and induction of chromosomal damage by vitamin $C$ in human lymphocyte cultures. Teratog Carcinog Mutagen. 1999;19:53-9 Available at: https://pubmed.ncbi.nlm.nih.gov/1 0321410/.

33. Halliwell B. Vitamin C: antioxidant or pro-oxidant in vivo? Free Radic Res. 1996:25(5):439-54. https://doi.org/10.3109/10715769609149066.
34. Vissers MCM, Das AB. Potential mechanisms of action for vitamin C in Cancer: reviewing the evidence. Front Physiol. 2018;9:809. https://doi.org/1 0.3389/fphys.2018.00809.

35. Broome SC, Woodhead JST, Merry TL. Mitochondria-targeted antioxidants and skeletal muscle function. Antioxidants (Basel). 2018;7(8). https://doi. org/10.3390/antiox7080107.

36. Smith RA, Murphy MP. Mitochondria-targeted antioxidants as therapies. Discov Med. 2011;11:106-14.

37. Jezek J, Engstova H, Jezek P. Antioxidant mechanism of mitochondriatargeted plastoquinone SkQ1 is suppressed in aglycemic HepG2 cells dependent on oxidative phosphorylation. Biochim Biophys Acta Bioenerg. 2017;1858(9):750-62. https://doi.org/10.1016/j.bbabio.2017.05.005.

38. Mendez D, et al. Mitoquinone (MitoQ) inhibits platelet activation steps by reducing ROS levels. Int J Mol Sci. 2020;21(17). https://doi.org/10.3390/ ijms21176192.

39. Li W, Ding Y. Cardiac preconditioning and cardiovascular diseases. Heart Mind. 2017;1:17-21. https://doi.org/10.4103/hm.hm_4_17.

40. Huang W, Cash N, Wen L, Szatmary P, Mukherjee R, Armstrong J, et al. Effects of the mitochondria-targeted antioxidant mitoquinone in murine acute pancreatitis. Mediat Inflamm. 2015;2015:901780-13. https://doi.org/1 $0.1155 / 2015 / 901780$

41. Plecita-Hlavata L, Jezek J, Jezek P. Pro-oxidant mitochondrial matrix-targeted ubiquinone MitoQ10 acts as anti-oxidant at retarded electron transport or proton pumping within complex I. Int J Biochem Cell Biol. 2009;41(8-9): 1697-707. https://doi.org/10.1016/j.biocel.2009.02.015.

42. Firsov AM, Kotova EA, Orlov VN, Antonenko YN, Skulachev VP. A mitochondria-targeted antioxidant can inhibit peroxidase activity of cytochrome c by detachment of the protein from liposomes. FEBS Lett. 2016;590(17):2836-43. https://doi.org/10.1002/1873-3468.12319.

43. Petrov A, Perekhvatova N, Skulachev M, Stein L, Ousler G. SkQ1 ophthalmic solution for dry eye treatment: results of a phase 2 safety and efficacy clinical study in the environment and during challenge in the controlled adverse environment model. Adv Ther. 2016;33(1):96-115. https://doi.org/1 0.1007/s12325-015-0274-5.

44. Kezic A, Spasojevic I, Lezaic V, Bajcetic M. Mitochondria-targeted antioxidants: future perspectives in kidney ischemia reperfusion injury. Oxidative Med Cell Longev. 2016;2016:2950503-12. https://doi.org/10.1155/2 016/2950503

45. Kuznetsov AV, Javadov S, Sickinger S, Frotschnig S, Grimm M. H9c2 and HL1 cells demonstrate distinct features of energy metabolism, mitochondrial function and sensitivity to hypoxia-reoxygenation. Biochim Biophys Acta. 2015;1853(2):276-84. https://doi.org/10.1016/j.bbamcr.2014.11.015.

46. Rao VA, Klein SR, Bonar SJ, Zielonka J, Mizuno N, Dickey JS, et al. The antioxidant transcription factor Nrf2 negatively regulates autophagy and growth arrest induced by the anticancer redox agent mitoquinone. J Biol Chem. 2010;285(45):34447-59. https://doi.org/10.1074/jbc.M110.133579.

47. Rao A, et al. The mitochondrially-targeted redox agent mitoquinone enhances doxorubicin-induced toxicity to breast cancer cells while protecting cardiac myocytes; 2007. p. S59.

48. Titova E, Shagieva G, Ivanova O, Domnina L, Domninskaya M, Strelkova O, et al. Mitochondria-targeted antioxidant SkQ1 suppresses fibrosarcoma and rhabdomyosarcoma tumour cell growth. Cell Cycle. 2018;17(14):1797-811. https://doi.org/10.1080/15384101.2018.1496748.

\section{Publisher's Note}

Springer Nature remains neutral with regard to jurisdictional claims in published maps and institutional affiliations.

Ready to submit your research? Choose BMC and benefit from:

- fast, convenient online submission

- thorough peer review by experienced researchers in your field

- rapid publication on acceptance

- support for research data, including large and complex data types

- gold Open Access which fosters wider collaboration and increased citations

- maximum visibility for your research: over $100 \mathrm{M}$ website views per year

At $\mathrm{BMC}$, research is always in progress.

Learn more biomedcentral.com/submission 